\title{
A ESTRATÉGIA DOS BÔNUS: TRÊS PRESSUPOSTOS E UMA CONSEQUÊNCIA
}

\author{
BONUS STRATEGY:THREE ASSUMPTIONS AND ONE CONSEQUENCE
}

Marcos Barbosa de Oliveira ${ }^{1}$

Resumo A 'estratégia dos bônus' é definida como a prática, por parte dos empregadores, de procurar fazer com que os empregados trabalhem mais e melhor usando como incentivo a concessão de vantagens monetárias adicionais ao salário, condicionadas ao aumento de produtividade. Dois exemplos da estratégia são mencionados, um deles referente à Secretaria da Educação do Estado de São Paulo, outro à Universidade de São Paulo. Examinam-se a seguir três pressupostos da estratégia - a concepção penosa do trabalho, o trabalhador imbuído do espírito do capitalismo e a recompensa monetária como única forma de incentivo - procurando-se mostrar que nenhum deles tem validade universal, sendo portanto estritamente falsos. Apresentam-se a seguir evidências adicionais para a invalidade dos pressupostos, oriundas do trabalho de professores aposentados, ou que já têm condições de se aposentar, mas continuam na ativa. Na última seção é exposta a consequência mais nefasta do uso da estratégia dos bônus: a 'idiotização' da sociedade.

Palavras-chave regime de trabalho; avaliação; remuneração por desempenho, cidadania.
Abstract The 'bonus strategy' is defined by employers as a way to seek to make the workers work more and better using grants for additional monetary benefits to wages as an incentive, conditional on an increase in productivity. Two examples of the strategy are mentioned, one of them referring to the Department of Education of the State of São Paulo and the other to the University of São Paulo (USP). It examines the following three assumptions of the strategy - the conception of painful labor, workers imbued with the spirit of capitalism, and monetary reward as the only form of incentive - in an attempt to show that none of them have universal validity and are therefore strictly false. Then we present the additional evidence for the invalidity of the assumptions, derived from the work of retired teachers and teachers who have the credentials to retire, but that are still working. In the last section, the most disastrous consequence of the use of the bonus strategy is exposed: the 'idiotization' of society. Keywords work regime, evaluation, pay for performance, citizenship. 


\section{Introdução: a estratégia dos bônus}

Este trabalho é fruto de um plano de estudos a que venho me dedicando a respeito dos processos de mercantilização que, na presente fase neoliberal do capitalismo, incidem sobre a Educação, a Ciência e - não como um setor ao lado desses dois, mas de um outro ponto de vista - a Universidade: o espaço institucional compartilhado pela educação superior e pela ciência. ${ }^{3}$ Entre tais processos, há os que envolvem mudanças no regime de trabalho - na educação básica, dos professores; na educação superior e na ciência, dos pesquisadores-professores, ou pesquisadores-docentes da universidade. Nessas mudanças, o papel principal é desempenhado pelas práticas de avaliação da produtividade que tanto se desenvolveram e tanto peso adquiriram nas últimas décadas. Um dos usos dos resultados das avaliações é o que se dá na estratégia dos bônus, que constitui o tema central deste ensaio. Vejamos então, para começar, em que consiste tal estratégia.

O objetivo primordial da administração do trabalho no capitalismo é o aumento da produtividade, tendo em vista a maximização do lucro. São várias as estratégias de que os empregadores se valem em função desse objetivo; uma delas é a que consiste em procurar fazer com que os empregados trabalhem mais e melhor usando como incentivo a concessão de vantagens monetárias adicionais ao salário, condicionadas ao aumento da produtividade. É uma estratégia antiga, incorporada com destaque no taylorismo (Taylor [1911], 2006, p. 88-89), que passou a ser utilizada muito mais amplamente na fase neoliberal do capitalismo, não apenas nas empresas privadas, mas também no serviço público. Vamos denominá-la 'estratégia dos bônus', independentemente da expressão usada para designá-la, que pode ser 'remuneração por desempenho', 'bonificação por resultados' (como se verá a seguir) etc.

Dois exemplos recentes da utilização da estratégia dos bônus no estado de São Paulo, um no nível da educação básica, outro no da universidade, são os seguintes.

No nível da educação básica, a Secretaria da Educação do Estado de São Paulo passou, em 6 de novembro de 2008, a resolução SE/74, que instituiu o Programa de Qualidade da Escola (PQE). O cerne do programa é um dispositivo de avaliação, do qual resulta um índice, o Idesp, tomado como um indicador de qualidade das escolas da rede estadual paulista. O Idesp é calculado com base em dois fatores: "I - o desempenho escolar, medido pelos resultados alcançados no Saresp (Sistema de Avaliação do Rendimento Escolar do estado de São Paulo); II - o fluxo escolar, qual seja, em quanto tempo os alunos aprenderam, medido pela taxa média de aprovação nas séries do Ensino Fundamental e do Ensino Médio." Essa resolução constituiu o primeiro passo de uma iniciativa, da qual o segundo foi dado com a promulgação pelo governador, José Serra, em 17 dezembro de 2008, da lei 
complementar $n .^{\circ} 1.078$, que "institui a bonificação por resultados (BR), no âmbito da Secretaria da Educação". A bonificação é paga aos professores e funcionários da rede gerida pela Secretaria, e é proporcional ao salário de cada um (podendo chegar a $20 \%$ ), sendo a proporção dependente do desempenho da escola, medido pelo Idesp.

No outro nível, a Universidade de São Paulo (USP), por meio da resolução n. ${ }^{0}$ 5.483, de 6 de novembro de 2008, instituiu o Prêmio de Excelência Acadêmica Institucional USP, com o objetivo de "reconhecer e valorizar as ações de seus docentes e servidores técnico-administrativos no desempenho de suas atividades que contribuem para o resultado institucional". O prêmio - um valor único para todos docentes e funcionários na ativa - é concedido anualmente, em duas parcelas. O 'resultado institucional' é avaliado por uma Comissão Gestora, tendo como critério três 'indicadores de desempenho' da universidade, a saber, "I - a avaliação continuada e trienal da pósgraduação pela Capes; II - a posição ocupada pela USP nos quatro rankings internacionais selecionados, que avaliam ensino e pesquisa, entre outros indicadores, a saber: Webometrics Ranking of World, Institute of Higher Education da Shanghai Jiao Tong University, Higher Education Evaluation \& Accreditation Council of Taiwan, e The Times Higher Education; III - a avaliação e o cumprimento dos planos de metas das unidades, que incluem metas para o ensino, pesquisa, e cultura e extensão, acompanhado pela Comissão Permanente de Avaliação (CPA)". Cabe à Comissão Gestora a decisão, a cada ano, de conceder ou não o prêmio e, em caso positivo, seu valor. 4

Vamos agora expor os três pressupostos a que o título faz menção, procurando mostrar que, embora cada um tenha seu lado verdadeiro, são todos carentes de validade universal, e portanto estritamente falsos.

\section{Primeiro pressuposto: a concepção penosa do trabalho}

O primeiro pressuposto é a concepção do trabalho como atividade penosa que os seres humanos só exercem quando premidos pela necessidade. Esta concepção tem uma longa história, estando presente já no "Ganharás o teu pão com o suor do teu rosto", do Antigo Testamento, e passando pela origem etimológica da palavra 'trabalho' no suplício do tripalium. Na modernidade, a concepção se reforça e se torna mais precisa na teoria e na prática do capitalismo. Na teoria, veja-se o que diz Adam Smith (ao defender sua teoria do valor-trabalho, $\mathrm{n}^{\prime}$ A riqueza das nações):

O verdadeiro preço de qualquer coisa, aquilo que ela efetivamente custa ao homem que a pretende adquirir, é a labuta e os incômodos (toil and trouble) a que é obrigado para a adquirir. Aquilo que efetivamente vale um objeto para o homem que o 
comprou e que pretende dispor dele ou trocá-lo por qualquer outra coisa é a labuta e os incômodos a que se poupa e que impõe a outras pessoas (Smith [1776], 1979, p. 27).

No seu estado normal de saúde, força e disposição, e com um grau normal de habilidade e destreza, ele [o trabalhador] deve sempre abrir mão da mesma quantidade de seu conforto, de sua liberdade e de sua felicidade (Smith [1776], 1979, p. 29).

Para Smith, portanto, trabalhar implica renunciar ao conforto, à liberdade e à felicidade.

Já no século XIX, Jevons é ainda mais explícito, definindo o trabalho como "o esforço penoso a que nos submetemos para evitar sofrimentos de maior intensidade, ou para obter prazeres que deixem um saldo a nosso favor" (Jevons [1871], 1983, p. 109). E na virada para o século XX, constatando o caráter consensual da concepção, tanto na linhagem do pensamento econômico a que Jevons pertence, quanto no senso comum, diz Veblen:

Um dos lugares-comuns da teoria econômica recebida é o de que o trabalho é desagradável [irksome]. Muitas discussões partem do axioma segundo o qual, com relação a questões econômicas, os homens desejam acima de tudo obter os bens produzidos pelo trabalho, e evitar o trabalho por meio do qual os bens são produzidos. De maneira geral, o senso comum está bem de acordo com a teoria corrente quanto a isso. No ideal do senso comum, a beatitude econômica reside num irrestrito consumo de bens, sem trabalho; enquanto o sofrimento econômico perfeito é o trabalho não remunerado (Veblen, 1898, p. 187).

Tal consenso permanece firme na ortodoxia neoclássica dominante nos dias de hoje, como um pressuposto fundamental, geralmente não explicitado nem discutido.

Quanto à prática, ou seja, a realidade social do capitalismo, basta lembrar que a forma paradigmática do trabalho, própria de seu momento inaugural, foi a dos moinhos satânicos da Revolução Industrial, para a qual seriam necessários adjetivos bem mais fortes que 'penoso' para caracterizar.

Contudo, não é necessário mais que o bom senso para mostrar que o pressuposto em pauta não é universalmente válido. Basta considerar a longa lista de atividades humanas que podem ser exercidas como trabalho, ou profissão, mas também na forma amadora, como prática de lazer, ou hobby. A lista de tais atividades, digamos assim, 'bi-valentes' inclui a culinária, a jardinagem, a pesca, bem como todas as atividades artísticas, artesanais, esportivas, e muitas outras. Não se quer com isso dizer que não haja diferença, em cada uma delas, quando praticadas em cada uma das modalidades. O importante é que não há razão de princípio para que um trabalhador, ao exercer uma delas profissionalmente, não tenha, pelo menos em parte, o mesmo tipo de 
satisfação intrínseca que tem quem a realiza como amador. Na medida em que proporciona algum grau de satisfação intrínseca, uma atividade, exercida profissionalmente, como trabalho, não é puramente penosa, e assim se refuta o primeiro pressuposto.

Existem naturalmente muitos tipos de trabalho necessários à manutenção da sociedade que dificilmente podem ser realizados de forma amadora. Mas é claro também que, ceteris paribus, uma sociedade será tanto melhor quanto mais próxima da forma amadora for a forma profissional de cada atividade, no que se refere à satisfação que proporciona. Retomaremos estas considerações a seguir, quando ficarão mais claras suas implicações.

\section{Segundo pressuposto: o trabalhador imbuído do espírito do capitalismo}

O segundo pressuposto da estratégia dos bônus é o de que, assim como o objetivo primordial do empresário é maximizar seu lucro, o do trabalhador é maximizar seus ganhos salariais, estando, dentro de seus limites físicos, sempre disposto trabalhar mais para ganhar mais.

Em A ética protestante e o espírito do capitalismo (Weber, [1904], 2004) encontra-se uma passagem muito interessante que expressa o essencial do que é necessário para mostrar que o pressuposto também não é universalmente válido. Nessa passagem, ao dar um exemplo concreto de 'tradicionalismo', Weber menciona o caso dos empresários do setor agrícola que, precisando de uma grande quantidade de trabalho na época da colheita, decidem aumentar o salário dos trabalhadores. O pagamento era feito modalidade 'salário por tarefa', e a ideia era a de que, tendo a oportunidade de conseguir ganhos excepcionalmente altos, eles iriam trabalhar com mais afinco, mais horas por dia. Eis como Weber descreve o resultado:

Só que aí surgiram dificuldades peculiares: o aumento do pagamento por tarefa o mais das vezes não teve por resultado maior produtividade do trabalho no mesmo intervalo de tempo, mas sim menor, porque os trabalhadores respondiam aos aumentos da taxa de remuneração não com o incremento da produtividade diária, mas sim com sua diminuição (Weber [1904], 2004, p. 52).

Para explicar o fenômeno, Weber prossegue, referindo-se ao trabalhador:

Ganhar mais o atraía menos que o fato de trabalhar menos; ele não se perguntava: quanto posso ganhar por dia se render o máximo no trabalho? e sim: quanto devo trabalhar para ganhar a mesma quantia - 2,50 marcos - que recebi até agora e que cobre as minhas necessidades tradicionais? Eis um exemplo justamente daquela atitude que deve ser chamada de 'tradicionalismo': o ser humano não quer 'por natureza' 
ganhar dinheiro e sempre mais dinheiro, mas simplesmente viver do modo como está habituado a viver e ganhar o necessário para tanto (Weber [1904], 2004, p. 53).

'Ganhar dinheiro e sempre mais dinheiro' é para Weber o summum bonum da ética própria do espírito do capitalismo. Mas se tal ética não é parte da natureza humana, tampouco o é a ética do tradicionalismo. Ambas são potencialidades da mente humana, plástica por natureza, as quais se realizam ou não dependendo da cultura em que o indivíduo se desenvolve. Dessa plasticidade se vale o capitalismo moderno que, ainda nas palavras de Weber, "dominando de longa data a vida econômica, educa e cria para si mesmo, por via da 'seleção' econômica, os sujeitos econômicos - empresários e operários - de que necessita" (Weber [1904], 2004, p. 46 e 48).

Concluindo: o segundo pressuposto da estratégia dos bônus só é válido para trabalhadores já imbuídos do espírito do capitalismo, porém o capitalismo dispõe de meios de criar trabalhadores com tal mentalidade. Essa faceta da questão é de grande importância, e a ela retornaremos no final desta exposição. Nos dias de hoje, o que almejam os professores cuja mentalidade ainda não foi colonizada pelo sistema não é propriamente "ganhar o necessário para viverem do modo como estão habituados", mas sim ganhar um salário suficiente para que possam levar uma vida digna, condizente com suas responsabilidades - além, naturalmente, de boas condições de trabalho, reconhecimento social etc. É disso que o professor precisa, não de bônus.

\section{Terceiro pressuposto: a recompensa monetária como única forma de incentivo}

O terceiro pressuposto afirma ser a obtenção de vantagens monetárias a única forma possível de incentivo à dedicação ao trabalho, e sua falsidade pode ser demonstrada a partir da mesma constatação que embasou a refutação do primeiro, a da existência de atividades 'bi-valentes'. Isso porque a expectativa de ter a satisfação intrínseca, essencial para que uma atividade possa ser exercida na forma amadora, pode naturalmente atuar como incentivo, mesmo quando a atividade é exercida profissionalmente. Mas vamos agora tratar da questão dos pontos de vista mais relevantes no presente contexto, isto é, com referência, primeiro ao trabalho docente, depois ao trabalho de pesquisa.

É impressionante como, no discurso neoliberal hegemônico nos dias de hoje referente à educação, em todos os níveis, adota-se como uma obviedade o pressuposto ora em pauta, quando o óbvio é justamente o contrário. Entre a miríade de exemplos que poderiam ser dados para substanciar essa afirmação, fiquemos com dois, um referente ao ensino fundamental, outro ao ensino superior. 
O primeiro vem de uma entrevista concedida por Eric Nadelstern e publicada nas páginas amarelas da revista Veja. Nadelstern (2007) é identificado na apresentação como " $C E O$ na secretaria da Educação da cidade de Nova York, de onde comanda uma das reformas mais radicais já feitas tendo como alvo uma rede tão grande de escolas públicas" (Nadelstern, 2007). Respondendo à pergunta 'Quais medidas se revelaram mais eficazes em sua própria experiência?', diz o entrevistado:

Para contar com uma tropa de gente decidida a fazer de determinada escola um exemplo de excelência, é preciso antes de tudo lhe dar incentivos concretos, tal qual ocorre em uma empresa privada. Não me refiro aqui apenas ao aumento de salário, que também ajuda, mas sobretudo a uma política de premiar com mais dinheiro diretores e professores que alcancem os melhores resultados. A Coreia do Sul já fez isso com sucesso e estamos colocando a ideia em prática agora em Nova York. Com a velha isonomia salarial, passamos uma mensagem equivocada do menor esforço, segundo a qual dar a alma ao trabalho não faz nenhum sentido (Nadelstern, 2007, p. 12).

O segundo exemplo, já mencionado em outra oportunidade (Oliveira, 2002, p. 37), é extraído de uma fala do professor Bresser-Pereira, proferida num debate com a professora Marilena Chauí realizado no contexto da greve que abalou as universidades públicas estaduais paulistas no ano 2000. Tratando da questão salarial, disse Bresser-Pereira:

Mas o drama também [...] é que a universidade trata todo mundo igual. Seja um professorzinho de baixíssima qualidade, com uma titulação da pior qualidade, seja uma Marilena Chauí, se for doutor ganha a mesma coisa. Ponto. É um escândalo isso. Não incentiva ninguém, não ajuda ninguém (Bresser-Pereira, 2000, p. 44).

Ou seja, para Nadelstern e Bresser-Pereira, assim como para todos os neoliberais que se ocupam dessas questões, a satisfação com o trabalho bem feito, a paixão intelectual, o reconhecimento dos colegas e alunos, o gosto de pertencer a uma instituição, orgulhar-se dela, e contribuir para seu fortalecimento, e para o bem de todos, tudo isso é irrelevante, incapaz de motivar o professor a se dedicar com mais afinco ao trabalho: se não há incentivo monetário, não há incentivo.

Muito poderia ser dito sobre tais motivações, ou valores, próprios das vocações do professor e do cientista. A satisfação com o trabalho bem feito, por exemplo, constitui o tema central de um livro recente de Richard Sennett, The craftsman. Sennett define craftsmanship como a habilidade, ou arte, de fazer bem as coisas ("the skill of making things well"), e diz o seguinte: 
Craftsmanship pode sugerir um modo de vida que depereceu com o advento da sociedade industrial - mas isso não é inteiramente verdadeiro. Craftsmanship designa um persistente e fundamental impulso humano, o desejo de fazer bem um trabalho como um fim em si mesmo. Craftsmanship envolve muito mais que trabalho manual especializado; motiva o programador de computadores, o médico, o artista; a criação dos filhos melhora quando é praticada como uma arte (a skilled craft), assim como a cidadania. (...) As condições sociais e econômicas, entretanto, frequentemente bloqueiam a disciplina e o empenho do craftsman: as escolas podem não fornecer os recursos para que se faça um bom trabalho, e os locais de trabalho podem não valorizar realmente a aspiração pela qualidade (Sennett, 2008, p. 9).

A partir de considerações deste gênero, seria possível argumentar que não se concebe um bom professor que não tenha a satisfação com o trabalho bem feito, a paixão intelectual etc., entre suas motivações dominantes. Mas em vez disso, no sentido de questionar o terceiro pressuposto da estratégia dos bônus, vamos desenvolver uma outra linha de raciocínio, a qual tem a forma lógica da redução ao absurdo. Vamos mostrar que a concepção do professor motivado apenas por vantagens monetárias está em contradição com um princípio básico norteador das práticas educativas, no Brasil e em muitos outros países, a saber, o que estabelece a preparação para o exercício da cidadania como uma das funções primordiais da Educação.

$\mathrm{Na}$ Constituição brasileira encontra-se o

Art. 205 - A educação, direito de todos e dever do Estado e da família, será promovida e incentivada com a colaboração da sociedade, visando ao pleno desenvolvimento da pessoa, seu preparo para o exercício da cidadania e sua qualificação para o trabalho (Brasil, 1988).

A Lei de Diretrizes e Bases da Educação Nacional, de 1996, reitera

Art. $2^{\circ}$ - A educação, dever da família e do Estado, inspirada nos princípios de liberdade e nos ideais de solidariedade humana, tem por finalidade o pleno desenvolvimento do educando, seu preparo para o exercício da cidadania e sua qualificação para o trabalho (Brasil, 1996).

E nos Parâmetros Curriculares Nacionais para o Ensino Fundamental, o tema é desenvolvido assim:

Numa democracia, o exercício da cidadania pressupõe a participação política de todos na definição de rumos que serão assumidos pela nação. As formas de participação política se expressam não só na escolha de representantes políticos e governantes, mas também na participação em movimentos sociais e mesmo no envolvimento dos 
sujeitos com temas e questões da vida da nação, envolvimento que se manifesta em todos os níveis da vida cotidiana, e mesmo nos espaços tradicionalmente considerados como da ordem da vida privada.

(...)

[A] participação política nas sociedades contemporâneas, além de continuar a exercer seu papel de assegurar o acesso igualitário dos cidadãos às instituições públicas construídas para garantir o gozo dos direitos sociais e individuais - saúde, educação, moradia, transporte, preservação ambiental e segurança pessoal - assume outras funções decorrentes da complexificação do mundo contemporâneo. Envolve, nos dias de hoje, não somente o controle público e democrático das instituições, mas também o engajamento no processo de criação de novas instituições e de novos direitos, em resposta à dinâmica cada vez mais acelerada de mudanças sociais.

(...)

O mundo contemporâneo coloca, mais do que nunca, a necessidade de que a educação trabalhe a formação ética dos alunos. Cabe à escola assumir-se enquanto instância de discussão dos referenciais éticos, não enquanto instância normativa e normatizadora, mas como espaço social de construção dos significados éticos necessários e constitutivos de toda e qualquer ação de cidadania.

(..)

É no horizonte de tal concepção de cidadania que a proposta dos PCNs se inscreve. Tais concepções são assumidas como o substrato que deve nortear, em nosso país, nos dias de hoje, uma proposta educacional (Brasil, 1997).

A ideia de cidadania contida nessas passagens provém, no essencial, da Grécia antiga, da vida na pólis. Em grego, '́́ðı (idios) refere-se ao que é

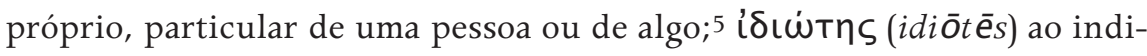
víduo preocupado apenas com seus interesses particulares, que não participa da vida pública - e, por extensão, à pessoa mal-educada, ignorante, estúpida. Utilizando o 'idiota' do português apenas na acepção primordial de 'idiōtēs', pode-se dizer que o professor pressuposto na estratégia dos bônus é o 'professor idiota' - a antítese do 'professor cidadão'.

Para responder à pergunta "Podem a ética e a cidadania ser ensinadas?", adotada como título de um artigo de sua autoria, J. S. de Carvalho diz, referindo-se à época da pólis, que

Tratava-se então - como se trata hoje - de se perguntar como formar o homem para que ele se torne um cidadão, um membro da coletividade que possa tomar para si as responsabilidades e o desafio de criar leis e princípios de convivência com o outro e com o público e conduzir-se de acordo com eles (Carvalho, 2004, p. 90).

E como proceder para formar os alunos para a cidadania? Recorrendo a Protágoras, responde o autor que tal formação é resultante "de um esforço 
educativo que não se separa dos próprios valores e procedimentos peculiares às instituições escolares e às disciplinas e conteúdos nela ensinados" (Carvalho, 2004, p. 98). O ensino dos valores da cidadania

(...) não é objeto de um momento especial, de uma preocupação pontual ou simplesmente de uma 'tematização transversal', à qual se expõe o aluno, como a um ponto do programa. Ao contrário, os princípios e valores característicos da instituição escolar estão contidos nos próprios conteúdos aprendidos, nas próprias formas de conhecimento ensinadas e, portanto, se encarnam nas atividades e práticas docentes que os materializam como conteúdos didáticos. Assim, o cultivo de valores fundamentais pode - e deve - estar presente no desenvolvimento de cada uma das atividades e disciplinas de nosso ensino (Carvalho, 2004, p. 99).

Com referência aos valores que animam as práticas do ensino e da ciência (mas numa afirmação que se aplica também aos valores da cidadania), diz o autor que o aprendizado

(...) não se dá pela sua simples veiculação verbal. Ao contrário, sua transmissão e preservação dependem das práticas sociais de seus agentes, da consciência que estes têm dos princípios que as animam e do significado de seus esforços no sentido de traduzi-las, aplicá-las e mantê-las vivas (Carvalho, 2004, p. 101).

Dito de um modo simplificado, isso significa que a formação para a cidadania só pode se realizar pelo exemplo. E como poderá o professor 'idiota', aquele cuja única motivação é a do autointeresse monetário, dar esse exemplo?

Podemos concluir então que o terceiro pressuposto da estratégia dos bônus implica, senão um absurdo no sentido lógico, algo de inadmissível, a saber, uma concepção da docência em completa contradição com princípios solidamente ancorados na legislação e no pensamento pedagógico em nosso país. Não seria despropositada, portanto, a afirmação de que é inconstitucional o emprego da estratégia dos bônus na administração do trabalho docente.

Vejamos agora as implicações do terceiro pressuposto no que se refere ao trabalho de pesquisa. Num escrito anterior (Oliveira, 2008; ver nota 2), procuramos mostrar que as práticas neoliberais de avaliação - a peça-chave do regime taylorista vigente na universidade -, pelo produtivismo e a competitividade exacerbada que promovem, não proporcionam ao pesquisador nem o tempo nem o espaço institucional necessários para a reflexão sobre o significado social do próprio trabalho, imprescindível para o exercício da responsabilidade social na ciência. A esse impedimento pode-se acrescentar agora um outro, que, na verdade, é logicamente anterior, a saber, que ao pesquisador ao qual se aplica o terceiro pressuposto - o pesquisador 'idiota' - 
falta a própria motivação para empreender tal reflexão, uma vez que ela não resulta em vantagens monetárias, nem em pontos no currículo.

\section{Evidências adicionais: aposentados e 'aposentandos'}

Ainda no contexto da universidade, e com relação agora aos três pressupostos, vejamos algumas evidências empíricas que os refutam mais diretamente. Elas dizem respeito aos pesquisadores-docentes aposentados, e aos 'aposentandos' - ou seja, os que continuam na ativa apesar de já satisfazerem os requisitos de tempo de contribuição e idade para se aposentarem. Quanto aos aposentados, o que se observa, pelo menos nas universidades públicas paulistas, é o grande número deles que continua trabalhando, às vezes até mais do que quando estavam na ativa, ou mantendo um vínculo com a pósgraduação, ou como free-lancers, escrevendo, dando palestras, organizando publicações, participando de bancas etc., em geral sem receber remuneração alguma. É desnecessário explicitar a contradição existente entre tais práticas e os pressupostos da estratégia dos bônus.

O mesmo vale para os 'aposentandos'. Com relação a estes, cabe notar que a partir de 2004, em decorrência da promulgação da emenda constitucional n. ${ }^{\circ} 41$, de 19 de dezembro de 2003, todos os servidores públicos 'aposentandos' do país (incluindo os pesquisadores-docentes da universidade) passaram a fazer jus a um 'abono de permanência', de valor igual ao de suas contribuições previdenciárias. Segundo o comentário de um jurista, um dos objetivos do abono é "incentivar o servidor que implementou os requisitos para aposentar-se a permanecer na ativa, pelo menos até a compulsória" (Sertão, 2005, p. 2). Não há dúvida de que, em relação a pesquisadores-docentes, tal incentivo é na grande maioria dos casos dispensável, pois mesmo antes da promulgação da emenda constitucional em pauta já era grande o número de 'aposentandos', e entre os que estão nesta situação agora, quase todos estariam mesmo sem o abono.

\section{A consequência mais nefasta: a 'idiotização' da sociedade}

A estratégia dos bônus tem naturalmente várias consequências, algumas delas nefastas - como, por exemplo, as fraudes cometidas por docentes e pesquisadores nas avaliações a que são submetidos, decorrentes da tendência inerente a esse sistema de fomentar comportamentos fraudulentos. 6 Nesta oportunidade trataremos apenas de uma delas, a mais nefasta de todas. Tomamos como ponto de partida a seguinte passagem de um sociólogo da ciência norte-americano, W. O. Hagstrom, em "A doação de presentes como princípio organizador da ciência": 
Um outro tipo de sanção que não é de grande importância na ciência, não obstante as frequentes alegações em contrário, consiste em recompensas extrínsecas, principalmente posição e dinheiro. Sustenta-se que os cientistas publicam, selecionam problemas e métodos a fim de maximizar tais recompensas. As políticas universitárias que baseiam a progressão na carreira e o salário na quantidade de publicações parecem implicar que isto seja verdade, que as contribuições de pesquisa dos cientistas não são de forma alguma dádivas, mas sim serviços em troca de salário. Embora seja importante que as recompensas extrínsecas sejam mais ou menos consistentes com o reconhecimento, o ideal é que elas sigam o reconhecimento, e esta parece ser a prática geral. De qualquer forma, a explicação do comportamento científico em termos de recompensas extrínsecas é enfraquecida pelo fato de que muitos cientistas em altas posições, cujas recompensas extrínsecas não são afetadas por seu comportamento, continuam sendo altamente produtivos, e adotando os objetivos e normas científicos. Além do mais, os cientistas em geral acham degradante e impróprio submeter manuscritos para publicação primordialmente para obter posições, sem se preocupar com que o trabalho seja lido por outros pesquisadores (Hagstrom, 1972, p. 114).

Publicado originalmente em 1965, o texto de Hagstrom7 deixa claro que, como muitos outros aspectos da reforma neoliberal da universidade, os agora em pauta não constituem propriamente novidades, mas sim uma intensificação de tendências preexistentes. Mas, independentemente disso, tanto o perfil do cientista que a passagem pressupõe quanto o do professor cidadão invocado acima, motivados por valores mais elevados que os monetários, são passíveis de um questionamento, baseado na alegação de que constituem concepções idealizadas, fruto de um wishful thinking, bem-intencionado mas ingênuo e ineficaz como fundamento de métodos de administração do trabalho. A premissa, no fundo, é a de que o impulso capitalista de 'ganhar dinheiro e sempre mais dinheiro' é parte da natureza humana. Algumas considerações já feitas são suficientes para mostrar que a crítica não procede. Porém é fundamental reconhecer que ela tem um lado verdadeiro, decorrente do fato de que professores e cientistas não são seres superiores, cujos valores provêm de um mundo platônico a-histórico: sendo dotados de uma mente que se caracteriza pela plasticidade, assim como todos os seres humanos, seus valores são moldados pela sociedade em que vivem, e em particular, do ponto de vista mais relevante no presente contexto, pelos valores incorporados nas instituições em que trabalham.

Essa moldagem é analisada por Lacey em "Para uma análise dos valores" (Lacey, 2008), no capítulo 2 de Valores e atividade científica 1, em termos das 'restrições' impostas aos valores sustentados por uma pessoa pelos valores predominantes na sociedade. Para ilustrar o papel das instituições nesse processo, Lacey observa que 
[O] local de trabalho moderno, industrial, é uma instituição que tem evoluído através dos séculos (com orientação, em vários pontos do percurso, de pessoas cujos interesses foram servidos por essa direção evolutiva particular) para tornar a manifestação de valores tais como a excelência, a solidariedade social, e o sentido no trabalho quase impossíveis. O local de trabalho moderno é conveniente para aqueles cuja visão do trabalho se restringe meramente a um meio adequado aos fins de acúmulo de riquezas e de consumo. Ele é conveniente para quem valoriza o individualismo e o egoísmo. É pouco conveniente para quem vê o trabalho como no mínimo parcialmente expressivo da personalidade, e expressivo de uma personalidade que está envolvida num projeto comunitário (Lacey, 2008, p. 59).

Pode-se dizer que esta passagem de Lacey complementa, com relação aos trabalhadores, a concepção de Weber, já mencionada, segundo a qual o capitalismo educa e cria para si mesmo os empresários e operários de que necessita. A análise da estratégia dos bônus apresentada sugere que o Estado, na forma que assume no neoliberalismo, também cria para si mesmo os professores e pesquisadores de que necessita - os professores e pesquisadores 'idiotas', para os quais são válidos os três pressupostos. E isso de fato acontece, significando que a estratégia dos bônus, num processo dialético, ao mesmo tempo pressupõe (falsamente) e cria (realmente) o professor e o pesquisador 'idiotas'.

Mas o processo não para aí: sendo 'idiotas', a atuação dos professores tende a formar alunos também 'idiotas', e o efeito global é a criação de uma sociedade de 'idiotas'.

Em Capitalism, socialism, democracy, Schumpeter defende a tese de que

Nenhum sistema social pode funcionar baseado exclusivamente numa rede de contratos livres entre partes contratantes (legalmente) iguais em que se supõe que cada indivíduo não é orientado por nada além de seus próprios fins utilitários (de curto prazo) (Schumpeter [1942], 1975, p. 417-8).

Ora, esse sistema social caracterizado por Schumpeter nada mais é senão a sociedade de 'idiotas'. Sua tese implica a necessidade de se construir uma sociedade de cidadãos, e constitui a razão mais fundamental para se resistir a tudo o que promove a 'idiotização' da sociedade, atuando no sentido oposto ao da emancipação humana. 


\section{Notas}

1 Professor Associado da Faculdade de Educação da Universidade de São Paulo (USP), São Paulo, Brasil. Doutor em História e Filosofia da Ciência pela Universidade de Londres. Pós-doutorados nas universidades de Essex, de Bristol, e na New School for Social Research, Nova York. Correspondência: Rua Rafael Clark, 76, Jardim Jussara, São Paulo, SP, CEP 05526-010.

2 Uma versão resumida deste trabalho foi apresentada na XII Conferência Anual da Associação Internacional para o Realismo Crítico, realizada em Niterói, de 23 a 25 de julho de 2009.

3 Resultados parciais desse estudo encontram-se em Oliveira (2002, 2004, 2005 e 2008).

4 Em 2008, o prêmio foi de $\mathrm{R} \$ 1.000,00$, sendo uma parcela de $\mathrm{R} \$ 500,00$, paga em novembro, outra em março de 2009.

5 Esta é a raiz presente, entre outras, nas palavras 'idiossincrasia' e 'idioma' (a língua própria de um povo).

6 Para um estudo sobre as fraudes cometidas por professores do ensino básico nos Estados Unidos, com o objetivo de incrementar as notas dos alunos nas avaliações a que estes são submetidos - e que em conjunto medem também o desempenho dos professores e das escolas - ver Levitt and Dubner, 2005, p. 24-35.

7 A fonte da citação, ou seja, o texto que figura na coletânea organizada por B. Barnes (ver referências bibliográficas) é um extrato do livro The scientific community (Hagstrom, 1965).

\section{Referências}

BRASIL. Constituição da República Federativa do Brasil. 1988. Disponível em: <www.planalto. gov.br/ccivil_03/Constituicao/constituiçao. htm>. Acesso em: 18 maio 2009.

Lei n. ${ }^{\circ}$ 9.394, de 20 de dezembro de 1996 (LDB). Estabelece as diretrizes e bases da educação nacional. Disponível em: <www.planalto.gov.br/ccivil_03/LEIS/19394 .htm >. Acesso em: 18 maio 2009.

Parâmetros Curriculares Nacionais para o Ensino Fundamental. 1997. Disponível em: <http://portaldoprofessor.mec.gov. br/linksCursosMateriais.html? categoria $=23>$. Acesso em: 18 maio 2009.
BRESSER-PEREIRA, Luiz Carlos. Reforma institucional, competitividade e autonomia financeira. Revista da Adusp, n. 21, 2000.

CARVALHO, José Sérgio. Podem a ética e a cidadania ser ensinadas? In: CARVALHO, José Sérgio (Org.). Educação, cidadania e direitos humanos. São Paulo: Vozes, 2004.

HAGSTROM, Warren O. The scientific community. Nova York: Basic Books, 1965.

Gift-giving as an organizing principle in science. In: BARNES, Barry (org.). Sociology of science. Harmondsworth: Penguin, 1972 . 
JEVONS, William S. A teoria da economia política [1871]. São Paulo: Abril Cultural, 1983.

LACEY, Hugh. Valores e atividade científica 1. São Paulo: Editora 34, 2008.

LEVITT, Steven D.; DUBNER, Stephen J. Freakonomics. Nova York: Harper-Collins, 2005.

NADELSTERN, Eric. Ensinar a competir. Entrevista concedida a Monica Weinberg. Revista Veja, n. 2.035, 21 nov. 2007.

OLIVEIRA, Marcos B. A ciência que queremos e a mercantilização da universidade. In: LOUREIRO, Isabel; DEL-MASSO, Maria C. (orgs.). Tempos de greve na universidade pública. Marília: Unesp Marília Publicações, 2002, p. 17-41. Disponível em: <http://paje. fe.usp.br $/ \sim$ mbarbosa $>$.

Desmercantilizar a tecnociência. In: SANTOS, Boaventura de S. (org.). Conhecimento prudente para uma vida decente: 'Um discurso sobre as ciências' revisitado. Edição portuguesa: Porto, Edições Afrontamento, p. 227-250, 2003. Edição brasileira: São Paulo, Cortez, p. 241-266, 2004. Disponível em: <http://paje.fe.usp.br/ mbarbosa $>$.

Ciência: força produtiva ou mercadoria? Crítica marxista 21, p. 77-96, 2005. Disponível em: <http://paje.fe.usp.br/ $\sim$ mbarbosa $>$.
. A avaliação neoliberal na universidade e a responsabilidade social dos pesquisadores. Scientiae Studia, v. 6, n. 3, p. 379-387, 2008. Disponível em: <http://paje.fe.usp.br/ $\sim$ mbarbosa $>$.

SCHUMPETER, Joseph A. Capitalism, socialism, democracy [1942]. 3. ed. Nova York: Harper \& Row, 1975.

SENNETT, Richard. The craftsman. New Haven e Londres: Yale University Press, 2008.

SERTÃO, A. S. L. Abono de permanência. Texto escrito em 2005. Disponível em: $<$ www.tce.pi.gov.br/documentos/artigos/ abono_permanencia.pdf $>$. Acesso em: 18 maio 2009.

SMITH, Adam. Investigação sobre a natureza e as causas da riqueza das nações [1776]. Coleção Pensadores, v. Adam Smith + David Ricardo. São Paulo: Abril Cultural, 1979.

TAYLOR, Frederick W. Princípios de administração científica [1911]. São Paulo: Atlas, 2006.

VEBLEN, Thorstein. The instinct of workmanship and the irksomeness of labor. American Journal of Sociology, v. 4, 1898.

WEBER, Max. A ética protestante e o 'espírito' do capitalismo [1904]. Ed. de Antônio Flávio Pierucci. São Paulo: Companhia das Letras, 2004.

Recebido em 28/07/2009

Aprovado em 18/10/2009 